\title{
Synthesis and Study of Good's Buffer Ionic Liquid as Corrosion Inhibitor for Carbon Steel in Acidic Medium
}

\author{
R. Nanthini ${ }^{1}$, KA Kurnia ${ }^{2}$ and MC Ismail ${ }^{3}$ \\ Master Student, Universiti Teknologi PETRONAS, Seri Iskandar, Perak, Malaysia
}

\begin{abstract}
The acid corrosion inhibition process of mild steel in $1 \mathrm{M}$ of $\mathrm{HCl}$ were studied from newly synthesized Ionic Liquid (ILs) from Good's buffer ionic liquid (GB-ILs) namely as [BMIM] [HEPES].GB-ILs are new class of ILs that are formed by the combination of Good's buffers as anions and various organic bases as cation. The inhibition efficiency has been investigated using weight loss measurement, electrochemical impedance (EIS) and potentiodynamic polarization. Ionic liquid tested as corrosion inhibitors after polarization curves displayed corrosion protection efficiency of $82 \%$ at 200 ppm for mild steel in a 1 M aqueous solution of hydrochloric acid. For all two inhibitors, the inhibition efficiency increased with increasing concentration of the inhibitors. The adsorption of the inhibitors on mild steel surface obeyed the Langmuir's adsorption isotherm. The surface morphology of the X52 mild steel was investigated using scanning electron microscopy (SEM) also shows unfailing result. As for ground work, the commercially available Good's Buffer inhibition performance studied alone as corrosion inhibitor and compared with the synthesised Ionic Liquid (GB-ILs) to appreciate the availability of the Ionic Liquid.
\end{abstract}

Keywords: Adsorption isotherm, Corrosion inhibitor, Ionic liquid, Langmuir, Linear polarization.

\section{Introduction}

Corosion of carbon steels is a common and inevitable problem in industries. It can be defined in many ways, but as common term corrosion is defined as 'an attack on metal contained material such as carbon steel by reaction with its environment'[1]. One of the most studied environments is acidic medium. Acidic solutions are substantially used in many industries processes such as acid descaling, acid pickling, industrial acid cleaning and oil well acidizing [1]. Hydrochloric acid is one of the most common types of corrosive acids used in the industrial operation. The aggressive condition often leads to corrosion.

Corrosion inhibitors are utilized to minimise the corrosive attack on metallic materials. Inhibitors are compounds that upon a small quantity of addition to corrosive medium, aid in reducing and controlling corrosion rate up to an acceptable level. Excellent organic inhibitors exhibit the property of having active functional groups. Organic inhibitors contain oxygen, nitrogen and/or sulphur atoms, heterocyclic compounds and electrons which they are adsorbed on the metallic surface forming a barrier and isolating the metal from corrosion [2]. Ionic liquids (ILs) are often described as salts with a melting point below $100{ }^{\circ} \mathrm{C}$. ILs made up entirely of ions and offers promising features as such high chemical stability whereby they can withstand degradation in control phase. Good thermal stability, high ionic conductivity [3] and wide electrochemical potential properties to facilitate good electrical conductivity [4]. Due to its low vapour pressure properties, ILs emerges as potential green solvents to substitute those volatile organic solvents [5]. In recent years, ILs has been studied as potential corrosion inhibitor in acidic medium .Zhang et al have conducted a study on the behaviour of ILs, namely 1butyl-3-methylimidazolium chloride for steel in acidic medium [6] and showed outstanding inhibition performance of the studied ILs for mild steel corrosion in acidic solution. Several imidazolium-based ILs have been reported to reduce the corrosion rate of mild steel in the acidic medium [7]. The presence of the aromatic 
group and availability of electronegative nitrogen in the molecules enable for such inhibition action. In the structure of the imidazolium bases, the atoms of the imidazolium ring and the $-\mathrm{C}=\mathrm{N}-$ group can form a big $\pi$ bond [8]. The electron of the imidazolium bases enters unoccupied orbitals of iron and $\pi$ orbital can also accept the electrons of $d$ orbitals of iron to form feedback bonds, resulting in high inhibition efficiency [9].

Good's buffers were developed by Good et al [10], for use as biological buffers with high buffering capacity at the physiological $\mathrm{pH}$ range. Good's buffers are non-toxic and widely used in biomedical processes. Tricine (N-(Tri(hydroxymethyl)methyl) glycine) has been tested in $0.5 \mathrm{M}$ chloride solution. The result indicated that is an effective green corrosion inhibitor for zinc as corrosion inhibitor [11]. Nevertheless, the use of Good's buffer ionic liquids as corrosion inhibitor is yet to be revealed in acidic medium with carbon steel. Aiming at this, two different Good's Buffer ILs as corrosion inhibitor will be studied in 1.0M hydrochloric acid medium at $25^{\circ} \mathrm{C}$.

\section{Materials and Methods}

\subsection{Material Preparation}

The sample selected for this study was steel API 5L X52 coupons with following composition (wt\%): 0.08 C, $1.06 \mathrm{Mn}, 0.26 \mathrm{Si}, 0.019 \mathrm{P}, 0.003 \mathrm{~S}, 0.0039 \mathrm{Al}, 0.041 \mathrm{Nb}, 0.018 \mathrm{Cs}, 0.02 \mathrm{Cr}, 0.019 \mathrm{Ni}, 0.054 \mathrm{~V}, 0.003 \mathrm{Ti}$, $0.0002 \mathrm{Ca}, 0.0003 \mathrm{~B}$ and the balance being Fe. Prior to all measurements, surface pre-treatment of mild steel was carried out by grinding and polishing to a mirror finish using 800, 1200 and 2400 grit emery paper and diamond paste [7]. Then, mild steel was immersed in ethanol, washed with double distilled water and finally dried before being weighed. The studied buffer, HEPES and TRICINE purchased from sigma Aldrich (98\% wt). The attack solution $(1 \mathrm{M} \mathrm{HCl})$ was prepared by dilution of analytical grade $37 \% \mathrm{HCl}$ in double distilled water. The buffer only solution concentration employed varied from $0.02 \mathrm{M}-0.08 \mathrm{M}$ for the ground work study and latter lowered to a range between $200 \mathrm{ppm}$ to $1000 \mathrm{ppm}$ for the synthesised ILs, [BMIM][HEPES] as to study the inhibitor efficiency at lower concentration. The ionic liquids were synthesized in two steps. In the first step,1butyl-3-methyl imidazolium hydroxide was synthesized in the solvent of ethanol. In the second step, anionic interchange of the hydroxide ion by Hepes was performed, following the general procedures described in the literature [12].

\subsection{Weight Loss Study.}

Weight loss experiments were carried out in a $100-\mathrm{mL}$ vessel placed in a constant temperature thermostat. Specimens with a dimension of $1.0 \mathrm{~cm} \times 1.0 \mathrm{~cm} \times 0.05 \mathrm{~cm}$ were immersed for a period of $24 \mathrm{~h}$ in $1 \mathrm{M} \mathrm{HCl}$ solution at $(298 \pm 1) \mathrm{K}$ containing various concentrations of the studied inhibitor. The specimens were then removed, carefully degreased, washed in double distilled water and prepared for weighing according to the standard ASTM G1 (Standard Practice for Preparing, Cleaning, and Evaluation Corrosion Test Specimens). Triplicate experiments were performed in each case and the mean value of weight loss was used for calculations.

\subsection{Electrochemical Analysis}

A three-electrode cell consisting of carbon coupons as working electrode, a platinum sheet with $1 \mathrm{~cm}^{2}$ surface area as a counter electrode and standard calomel electrode as a reference electrode were used [13]. The experiment was carried out in a beaker containing the $100 \mathrm{ml}$ of corrosive solution $(1.0 \mathrm{M} \mathrm{HCl})$ connected to PC through the General Purpose Electrochemical System (GPES) software provided by AUTOLAB. Prior to all electrochemical measurement, stabilisation period of 30 minutes allowed which proved sufficient for open circuit potential $\left(E_{\text {ocp }}\right)$ to attain a reliable stable value [8]. The scan rate was set at $10 \mathrm{mV} / \mathrm{minute}$. Tafel plot was obtained in the potential range of $-300 \mathrm{mV}$ to $+300 \mathrm{mV}$. EIS measurement was carried out in the frequency range of $100 \mathrm{KHz}$ to $0.1 \mathrm{~Hz}$ with amplitude of $10 \mathrm{mV}$ using alternating current (AC). All electrochemical tests have been performed in non-deaerated solutions under unstirred conditions. Each electrochemical measurement was repeated three times [14] under the same conditions and mean values of certain parameters, such as Tafel slopes, corrosion current density and charge transfer resistance recorded to ensure reliability. 


\subsection{Microstructure}

The respective morphology of the carbon steel API 5L X52 after its exposure to $1.0 \mathrm{M} \mathrm{HCl}$ solutions in the absence and presence of various concentrations of inhibitors was studied by scanning electron microscopy (SEM). The SEM images were taken using the model of Zeiss Supra 55 VP.

\section{Result and Discussion}

\subsection{Weight Loss Measurement}

The weight loss of the carbon steel coupons in $1.0 \mathrm{M} \mathrm{HCl}$ with the absence and presence of different concentrations of buffer only solutions $(0.02-0.08 \mathrm{M})$ were obtained after 24 -hour immersion at $25{ }^{\circ} \mathrm{C}$. The inhibition efficiency, (IE \%) was calculated using following equation:

$I E \%=\left(\frac{W-W_{i n h}}{W}\right) \times 100$

Where $\mathrm{W}$ correspond to the weight loss of carbon coupons in the absence of the inhibitors and Winh in the presence of the inhibitor.

TABLE I: Weight Loss data For Mild Steel In The Presence And Absence Of Different Concentrations Of Buffer Only In $1.0 \mathrm{M} \mathrm{HCl} \mathrm{Solution}$

\begin{tabular}{|c|c|c|c|}
\hline Concentration (M) & Concentration (ppm) & IE \% & Surface Coverage $(\Theta)$ \\
\hline & $1 \mathrm{M} \mathrm{HCl}$ blank & 0 & 0 \\
\hline \multicolumn{4}{|l|}{ HEPES } \\
\hline 0.02 & 4766 & 20.17 & 0.2017 \\
\hline 0.04 & 9532 & 21.48 & 0.2148 \\
\hline 0.06 & 14298 & 23.58 & 0.2358 \\
\hline 0.08 & 19641 & 25.44 & 0.2544 \\
\hline
\end{tabular}

The result plotted in Table I is then compared with the weight loss for the synthesised buffer Ils in the concentration range between $200 \mathrm{ppm}$ to $1000 \mathrm{ppm}$ as shown in Table II. For consistency purposes all the concentration unit listed in ppm.

TABLE II: Weight Loss data For Mild Steel In The Presence And Absence Of Different Concentrations Of Ionic Liquids In $1.0 \mathrm{M} \mathrm{HCl}$ Solution

\begin{tabular}{lcc}
\hline $\begin{array}{l}\text { Concentration } \\
(\mathrm{ppm})\end{array}$ & IE \% & Surface Coverage $(\theta)$ \\
\hline 1 M HCl blank & 0 & 0 \\
\hline BMIM HEPES & & 0.7987 \\
200 & 79.87 & 0.805 \\
400 & 80.5 & 0.8081 \\
600 & 80.81 & 0.8144 \\
800 & 81.44 & 0.8459 \\
1000 & 84.59 & 0 \\
\hline \hline
\end{tabular}

The inhibition efficiency increases with the increase in the concentrations of the inhibitors [15]. These results in Table 1 indicated that the presence of buffer could only reduce the corrosion rate of carbon steel in the acidic medium up to $34 \%$. Meanwhile in the presence of ILs, better inhibition is contributed and measures up to $85 \%$. The large surface coverage, provided with increasing ILs inhibitor concentrations delays the hydrogen and metal dissolution directly by blocking the active sites available for corrosion [16]. From weight loss measurement, it is worth mentioning that the presence of cation and anion plays a significant role on the corrosion behaviour of ionic liquids towards the mild steel [3].

\subsection{Electrochemical impedance spectroscopy}

Electrochemical impedance spectroscopic (EIS) studies have further been conducted to investigate corrosion inhibition processes in terms of the resistive as well as capacitive behaviour at metal/solution interface. The effect of different concentration of the synthesised ILs studied through the impedance behaviour of the carbon steel in $1.0 \mathrm{M} \mathrm{HCl}$ solution. 
In the presence of ILs, the electrochemical impedance spectra (Nyquist plots) characterized by one semicircle, whose centre lies under the real axis as shown in Fig. 1a. The best fit equivalent circuit applied for fitting of the impedance data includes the polarization resistance Rct in parallel to the constant phase element (Cdl) connected with the solution resistance Rs [17] presented in Fig 2. Fig. 1 represent impedance spectra includes (a) Nyquist, (b) Bode-module (c) and Bode-phase angle plot for carbon steel in $1.0 \mathrm{M} \mathrm{HCl}$ after immersion with and without IL of [BMIM] [HEPES].

a)

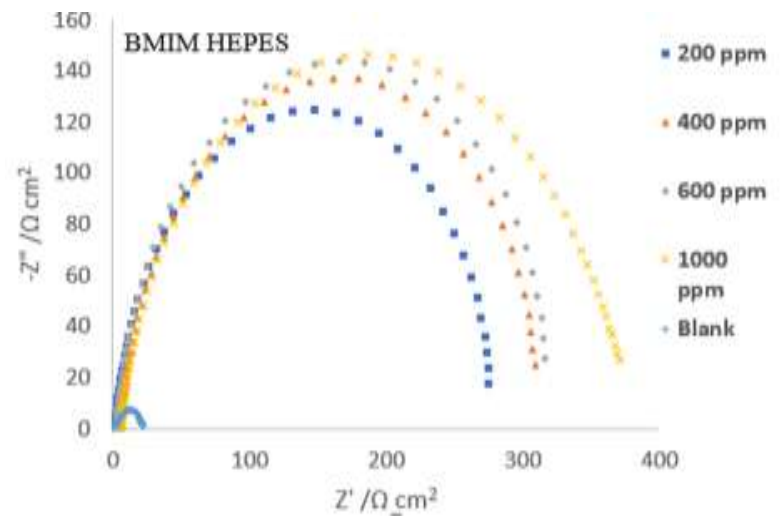

b)

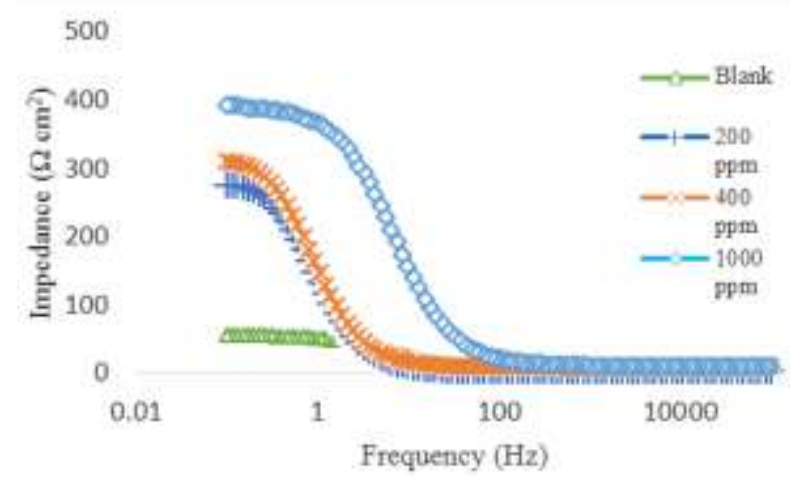

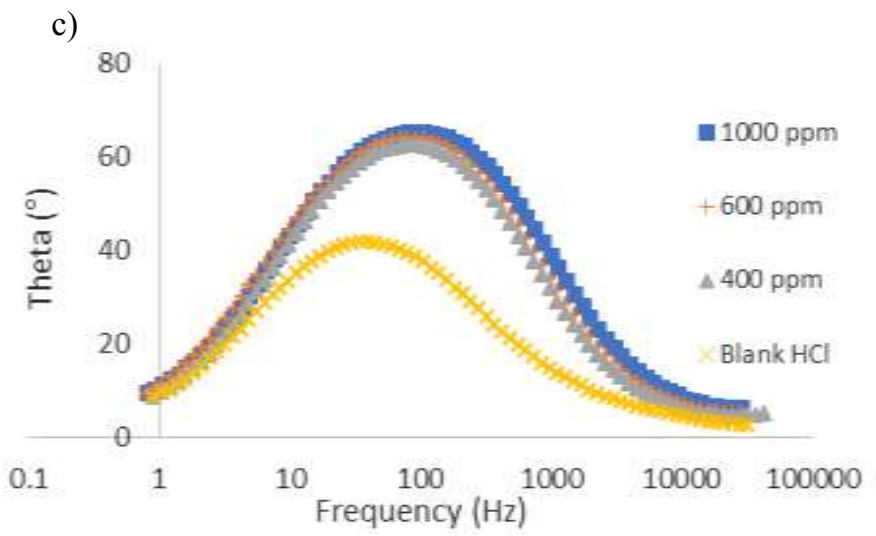

Fig. 1: Impedance spectra includes (a) Nyquist, (b) Bode-module (c) and Bode-phase angle plots for carbon steel in 1.0 M $\mathrm{HCl}$ in absence and presence of various concentration of [BMIM][HEPES]

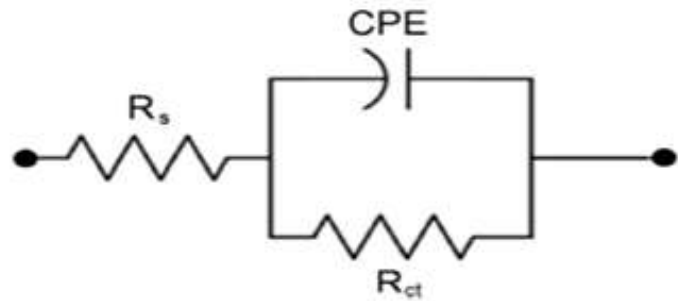

Fig. 2: Equivalent circuit for fitting of impedance data

From Fig. 1a, the obtained Nyquist plot is semicircular in shape for the respective IL of [BMIM] [HEPES] indicating that charge transfer process mainly controls the corrosion in this studied environment. The diameter of the capacitive loop in the presence of inhibitor is larger as compared to the uninhibited system and increases with the increase in concentration of the inhibitor [18] . Similar pattern is shown in Bode-modulus plot as in Fig. 1b. In the presence of ionic liquid inhibitor, the value of Rct have enhanced meanwhile the value of Cdl reduces as in Table III. The reduction in the Cdl value in the presence of inhibitor due to increase in the thickness of the electric double layer, suggesting water molecules are being replaced by ionic liquid molecules [19]. 
TABLE III: EIS Data for Mild Steel in the Presence and Absence of Different Concentrations of Ionic Liquid in $1.0 \mathrm{M} \mathrm{HCl} \mathrm{Solution}$

\begin{tabular}{llll}
\hline \hline Concentration $(\mathrm{ppm})$ & $\begin{array}{l}\mathrm{R}_{\mathrm{ct}} \\
\left(\Omega \mathrm{cm}^{2}\right)\end{array}$ & $\begin{array}{l}\mathrm{C}_{\mathrm{dl}} \\
(\mu \mathrm{F} \mathrm{cm})\end{array}$ & $I E \%$ \\
\hline Blank & 45 & 375 & - \\
\hline 200 & 245 & 184 & 82 \\
400 & 302 & 119 & 85 \\
600 & 319 & 107 & 86 \\
800 & 388 & 78 & 88 \\
1000 & 450 & 48 & 91 \\
\hline
\end{tabular}

In this EIS measurement, inhibition efficiency (IE \%) is calculated using charge transfer resistance as shown in (2)

$$
I E \%=\frac{R_{t}^{i n h}-R_{t}}{R_{t}^{i n h}} \times 100 \%
$$

Where $R_{t}^{i n h}$ and $R_{t}$ are the charge transfer resistance values with and without inhibitors for carbon steel in $1.0 \mathrm{M} \mathrm{HCl}$, respectively. It is clear from the data that inhibition efficiency (IE \%) increases with increasing concentration of inhibitor [20].

Besides, from the obtained Bode-phase angle plots as in Fig. 1c shows that maximum phase angle increases with increasing concentration of [BMIM] [HEPES] inhibitor. This signify the increase of capacitive response with IL concentration [12]. In other word, this can be related to adsorption of inhibitor molecules on the respective steel surface [21].

\subsection{Polarization Measurement}

The inhibition efficiency of ionic liquid of [BMIM] [HEPES] on the corrosion behaviour of carbon steel in $1.0 \mathrm{M} \mathrm{HCl}$ was investigated using polarization curves. Fig. 2 represents the polarization curves for [BMIM][HEPES] at $298 \mathrm{~K}$. The polarization parameters such as; corrosion potential (Ecorr) and corrosion current density (Icorr), with the corresponding inhibition efficiency (IE \%) were measured and listed as in Table IV. The IE \% was calculated as shown in (3):

$$
I E \%=\frac{I_{c o r r}^{o}-I_{\text {corr }}}{I_{\text {corr }}^{o}} \times 100 \%
$$

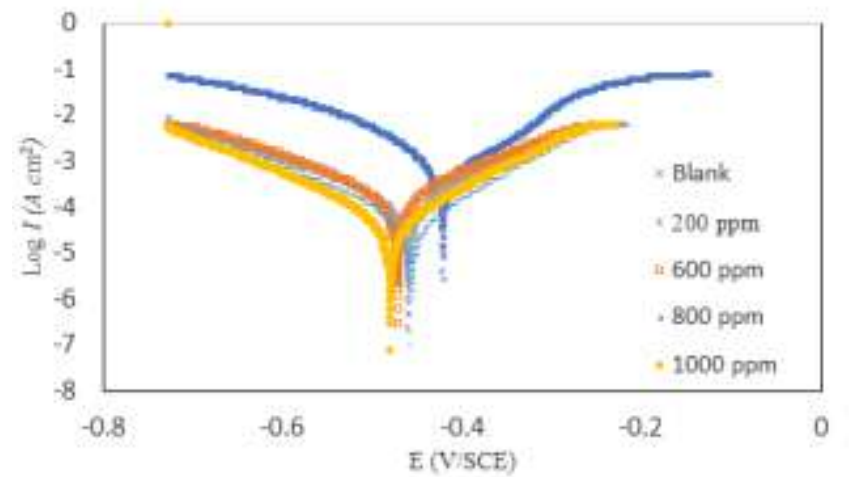

Fig 3 Polarization curve for carbon steel in $1 \mathrm{M} \mathrm{HCl}$ with and without [BMIM] [HEPES]

TABLE IV: Tafel data For Mild Steel In The Presence And Absence Of Different Concentrations Of Ionic Liquid In $1.0 \mathrm{M}$ $\mathrm{HCl}$ Solution

\begin{tabular}{cccc}
\hline \hline Concentration (ppm) & $\begin{array}{c}\mathrm{I}_{\text {corr }} \\
\left(\mu \mathrm{A} \mathrm{cm}^{-2}\right)\end{array}$ & $\begin{array}{c}\mathrm{E}_{\text {corr }} \\
\mathrm{mV}\end{array}$ & IE\% \\
\hline Blank & 1130 & 420 & - \\
\hline 200 & 255 & 456 & 77 \\
400 & 140 & 461 & 87 \\
600 & 105 & 457 & 90 \\
100 & 87 & 460 & 93 \\
\hline \hline
\end{tabular}


From the data of Fig 3 and Table IV, it can be observed that the presence of ionic liquid has a great role in reducing corrosion of carbon steel in acidic environment. This can be concluded from the decreasing value of corrosion current density (Icorr) [22]. It is worth to mention that good inhibition efficiency is obtained even at lowest concentration $(200 \mathrm{ppm})$. The inhibition efficiency increases with increase in ionic liquid inhibitor concentration indicating decrease in metal dissolution rate [12], [23].

The variation in inhibitor efficiency able to reflect a structural difference and thus producing corresponding change of interaction between mild steel surface and the respective inhibitor [24]. No definite trend was observed in the shifts of corrosion potential. The displacement in the corrosion potential ( \pm less than $85 \mathrm{mV}$ ) in relation to the blank solution might indicate a mixed-type inhibitor [25]. This indicates that addition of inhibitor reduces the metal dissolution at the anodic and retards hydrogen evolution at the cathodic. The reduction of corrosion products such as oxides in acidic medium allows better adsorption of the inhibitor and decreases the proton diffusion to the metal/solution interface [26]. Thus it can deduced that the results of inhibition efficiency (IE \%) from weight loss measurement, electrochemical impedance and polarization measurement are in good agreement with one another.

\subsection{Scanning Electron Microscopy}

To confirm the formation of the films on the steel surface, the SEM technique was used to characterize the mild steel surface [27]. Fig 3, represents the morphology of the exposed bare steel in $1 \mathrm{M} \mathrm{HCl}$ aqueous solution and in varying concentrations of buffer only solutions respectively. Fig 3a reveals the steel surface after a $24 \mathrm{~h}$ immersion in uninhibited $1 \mathrm{M} \mathrm{HCl}$. Aggressive attack and damage with a great deal of deep cavities were found [23]. Fig 3b-d, present the images of the iron sheet covered by HEPES buffer film after immersion in different concentrations of buffer only solutions in acidic medium. However, under the same corrosion circumstances, the surface of film-modified steel sheet (Fig 3b-d) was comparably cleaner and small pits are still visible on the steel surface with increasing inhibitor concentrations. Inspection of the morphologies implied that the presence of the buffer solution films able protect the steel from corrosion but only in limited range.

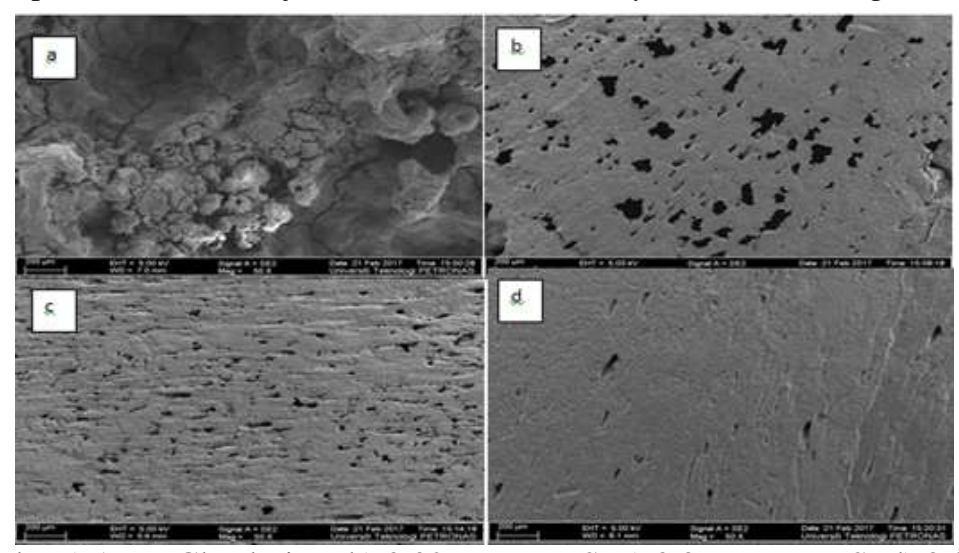

Fig 3 SEM for HEPES buffer only. a) 1M HCl solution; b) 0.02 M HEPES; c) 0.06 M HEPES; d) 0.08 M HEPES solution

This is then compared with the carbon steel immersion in respective synthesized buffer ILs [BMIM][HEPES] solution with varying concentration between 200 to $1000 \mathrm{ppm}$. SEM images of the carbon steel surfaces in varying concentration in $1.0 \mathrm{M} \mathrm{HCl}$ solution exhibit the changes which occurred during corrosion process in absence and presence of inhibitor. Carbon steel surface in hydrochloric acid was drastically damaged [6] and in presence of $200 \mathrm{ppm}$ up to $1000 \mathrm{ppm}$ of buffer ILs of [BMIM][HEPES] (Fig.4b-d) surface was remarkably improved. 


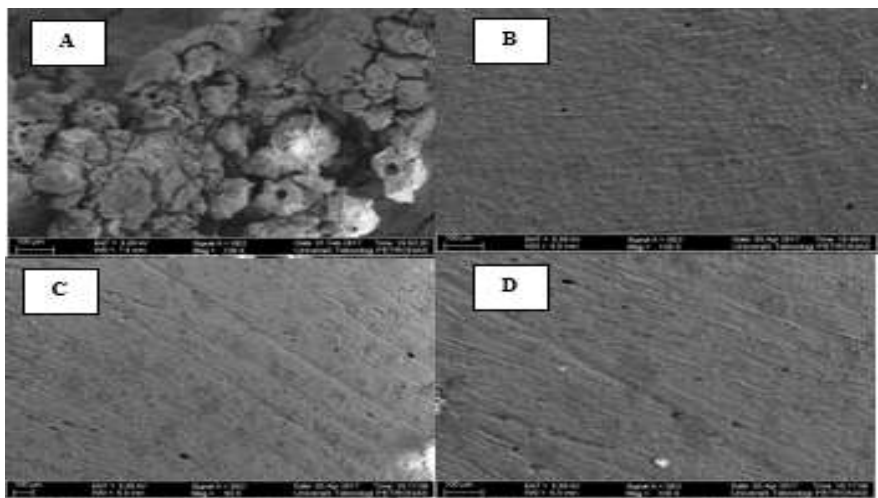

Fig 4 SEM for [BMIM] [HEPES]. a) 1M HCl solution; b) 200 ppm; c) 600 ppm; d) 800 ppm

Inspection of the morphologies implied that the presence of the ILs solution films can efficiently protect the steel from corrosion. Moreover, the formation of self-assembled films at the surface of steel increases the interaction between ILs solutions with the steel surface, resulting in a decrease in the contact between the steel and the aggressive medium [28] This improvement in surface morphology indicates the formation of a good protective film on carbon steel surface which is responsible for inhibition even though applied in smaller concentration.

\subsection{Adsorption Isotherm}

The information on the interaction between the inhibitor molecules of ILs and carbon steel surfaces can be provided by adsorption isotherms. Inhibitor molecules undergo two types of adsorption with the metal surface. One of it will be physical adsorption (physisorption) [29] which results on the electrostatic attraction between inhibiting organic ion with the electrically charged metal surface. Charge sharing or charge transfer from adsorbates to the metal surface atoms to form a covalent type of bond are regarded as chemical adsorption (chemisorption) [4].

The degree of surface coverage $(\Theta)$ for different concentration of the Ils inhibitors was evaluated from weight loss data [30]. Attempts were made to fit $\Theta$ values to various isotherms including Langmuir, Temkin and Freundlich. It was found that the data best fit was obtained through Langmuir isotherms as shown in Fig 5. The regression coefficient is almost unity [31].

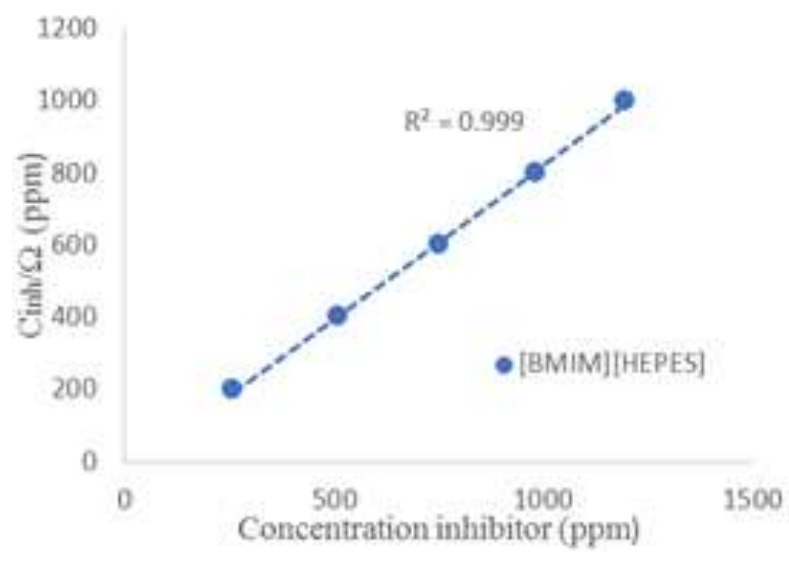

Fig 5 Langmuir Adsorption Isotherm of [BMIM][HEPES]

\section{Conclusion}

All the measurements show that the imidazolium which acting as the cation and buffer as anion contributes to the adsorption respectively and aids in inhibiting corrosion in acidic medium. Therefore, it is worthwhile to 
consider the usage of ionic liquids as corrosion inhibitor especially in dynamic environments such as in steel pipeline solution flow.

\section{Acknowledgements}

This project is funded by Yayasan Universiti Teknologi PETRONAS through Fundamental Research Grant Scheme (YUTP-FRG/2016/0153AA-E31).N.R would like to acknowledge UTP for the Graduate Assistance Scheme.

\section{References}

[1] A. Singha and M. A. Quraishi, “Acidizing corrosion inhibitors: A review," J. Mater. Environ. Sci., vol. 6, no. 1, pp. 224-235, 2015.

[2] V. S. Sastri, E. Ghali, and M. Elboujdaini, "Introduction and Principles of Corrosion," Corros. Prev. Prot. Pract. Solut., 2007.

[3] A. M. El-Shamy, K. Zakaria, M. A. Abbas, and S. Zein El Abedin, "Anti-bacterial and anti-corrosion effects of the ionic liquid 1-butyl-1-methylpyrrolidinium trifluoromethylsulfonate," J. Mol. Liq., vol. 211, pp. 363-369, 2015.

[4] A. A. Al-Amiery, A. A. H. Kadhum, A. H. M. Alobaidy, A. B. Mohamad, and P. S. Hoon, "Novel corrosion inhibitor for mild steel in HCL," Materials (Basel)., vol. 7, no. 2, pp. 662-672, 2014.

[5] C. Gabler, C. Tomastik, J. Brenner, L. Pisarova, N. Doerr, and G. Allmaier, "Corrosion properties of ammonium based ionic liquids evaluated by SEM-EDX, XPS and ICP-OES,” Green Chem., vol. 13, no. 10, p. 2869, 2011.

[6] D. Zhang, Y. Tang, S. Qi, D. Dong, H. Cang, and G. Lu, "The inhibition performance of long-chain alkylsubstituted benzimidazole derivatives for corrosion of mild steel in HCl," Corros. Sci., vol. 102, pp. 517-522, 2016.

[7] M. Bouklah, M. Kaddouri, Y. Toubi, B. Hammouti, S. Radi, and E. E. Ebenso, "Corrosion Inhibition of Steel in Hydrochloric Acid Solution by New N , N ’ -Bipyrazole Piperazine Derivatives,” vol. 8, pp. 7437-7454, 2013.

[8] N. V. Likhanova, M. A. Domínguez-Aguilar, O. Olivares-Xometl, N. Nava-Entzana, E. Arce, and H. Dorantes, "The effect of ionic liquids with imidazolium and pyridinium cations on the corrosion inhibition of mild steel in acidic environment," Corros. Sci., vol. 52, no. 6, pp. 2088-2097, 2010.

[9] M. Mobin, R. Aslam, and J. Aslam, "Non toxic biodegradable cationic gemini surfactants as novel corrosion inhibitor for mild steel in hydrochloric acid medium and synergistic effect of sodium salicylate: Experimental and theoretical approach," Mater. Chem. Phys., vol. 191, pp. 151-167, 2017.

[10] M. Taha, F. A. e Silva, M. V. Quental, S. P. M. Ventura, M. G. Freire, and J. A. P. Coutinho, "Good's buffers as a basis for developing self-buffering and biocompatible ionic liquids for biological research," Green Chem., vol. 16, no. 6, pp. 3149-3159, 2014.

[11] H. Nady, "Tricine [ N- ( Tri ( hydroxymethyl ) methyl ) glycine ] - A novel green inhibitor for the corrosion inhibition of zinc in neutral aerated sodium chloride solution," Egypt. J. Pet., 2016.

[12] M. Bouanis, M. Tourabi, A. Nyassi, A. Zarrouk, C. Jama, and F. Bentiss, "Corrosion inhibition performance of 2,5bis(4-dimethylaminophenyl)-1,3,4-oxadiazole for carbon steel in $\mathrm{HCl}$ solution: Gravimetric, electrochemical and XPS studies," Appl. Surf. Sci., vol. 389, pp. 952-966, 2016.

[13] E. Kowsari et al., "In situ synthesis, electrochemical and quantum chemical analysis of an amino acid-derived ionic liquid inhibitor for corrosion protection of mild steel in 1M HCl solution,” Corros. Sci., vol. 112, pp. 73-85, 2016.

[14] H. M. Abd El-Lateef, A. M. Abu-Dief, and M. A. A. Mohamed, "Corrosion inhibition of carbon steel pipelines by some novel Schiff base compounds during acidizing treatment of oil wells studied by electrochemical and quantum chemical methods," J. Mol. Struct., vol. 1130, pp. 522-542, 2017.

[15] S. K. Shukla, L. C. Murulana, and E. E. Ebenso, "Inhibitive effect of imidazolium based aprotic ionic liquids on mild steel corrosion in hydrochloric acid medium," Int. J. Electrochem. Sci., vol. 6, no. 9, pp. 4286-4295, 2011. 
[16] H. Ashassi-Sorkhabi and M. Es'haghi, "Corrosion inhibition of mild steel in acidic media by [BMIm]Br Ionic liquid," Mater. Chem. Phys., vol. 114, no. 1, pp. 267-271, 2009.

[17] N. Yilmaz, A. Fitoz, Ü. Ergun, and K. C. Emregül, "A combined electrochemical and theoretical study into the effect of 2-((thiazole-2-ylimino)methyl)phenol as a corrosion inhibitor for mild steel in a highly acidic environment," Corros. Sci., vol. 111, pp. 110-120, 2016.

[18] L. Herrag, A. Chetouani, S. Elkadiri, B. Hammouti, and A. Aouniti, "Pyrazole derivatives as corrosion inhibitors for steel in hydrochloric acid," Port. Electrochim. Acta, vol. 26, no. 2, pp. 211-220, 2008.

[19] A. Hamdy and N. S. El-Gendy, "Thermodynamic, adsorption and electrochemical studies for corrosion inhibition of carbon steel by henna extract in acid medium,” Egypt. J. Pet., vol. 22, no. 1, pp. 17-25, 2013.

[20] M. A. Deyab, M. T. Zaky, and M. I. Nessim, "Inhibition of acid corrosion of carbon steel using four imidazolium tetrafluoroborates ionic liquids,” J. Mol. Liq., vol. 229, pp. 396-404, 2017.

[21] Q. Zhang and Y. Hua, "Corrosion inhibition of aluminum in hydrochloric acid solution by alkylimidazolium ionic liquids," Mater. Chem. Phys., vol. 119, no. 1-2, pp. 57-64, 2010.

[22] J. B. Pérez-Navarrete, C. O. Olivares-Xometl, and N. V. Likhanova, "Adsorption and corrosion inhibition of amphiphilic compounds on steel pipeline grade API 5L X52 in sulphuric acid 1 M," J. Appl. Electrochem., vol. 40, no. 9, pp. 1605-1617, 2010.

[23] M. Yadav, P. N. Yadav, and U. Sharma, "Substituted imidazoles as corrosion inhibitors for N80 steel in hydrochloric acid," Indian J. Chem. Technol., vol. 20, no. 6, pp. 363-370, 2013.

[24] A. Sosnowska, M. Barycki, M. Zaborowska, A. Rybinska, and T. Puzyn, "Towards designing environmentally safe ionic liquids: the influence of the cation structure," Green Chem., vol. 16, no. 11, pp. 4749-4757, 2014.

[25] M. A. Quraishi, A. Singh, V. K. Singh, D. K. Yadav, and A. K. Singh, "Green approach to corrosion inhibition of mild steel in hydrochloric acid and sulphuric acid solutions by the extract of Murraya koenigii leaves," Mater. Chem. Phys., vol. 122, no. 1, pp. 114-122, 2010.

[26] P. Kannan, J. Karthikeyan, P. Murugan, T. S. Rao, and N. Rajendran, "Corrosion Inhibition effect of novel methyl benzimidazolium Ionic liquid for carbon steel in $\mathrm{HCl}$ medium," J. Mol. Liq., vol. 221, pp. 368-380, 2016.

[27] I. Lozano, E. Mazario, C. O. Olivares-Xometl, N. V. Likhanova, and P. Herrasti, "Corrosion behaviour of API 5LX52 steel in $\mathrm{HCl}$ and $\mathrm{H} 2 \mathrm{SO} 4$ media in the presence of 1,3-dibencilimidazolio acetate and 1,3-dibencilimidazolio dodecanoate ionic liquids as inhibitors," Mater. Chem. Phys., vol. 147, no. 1-2, pp. 191-197, 2014.

[28] X. Zheng, S. Zhang, W. Li, M. Gong, and L. Yin, "and theoretical studies of two imidazolium-based ionic liquids as inhibitors fExperimentalor mild steel in sulfuric acid solution," Corros. Sci., vol. 95, pp. 168-179, 2015.

[29] K. F. Khaled and A. El-Maghraby, "Experimental, Monte Carlo and molecular dynamics simulations to investigate corrosion inhibition of mild steel in hydrochloric acid solutions," Arab. J. Chem., vol. 7, no. 3, pp. 319-326, 2014.

[30] P. Mourya, S. Banerjee, and M. M. Singh, "Corrosion inhibition of mild steel in acidic solution by Tagetes erecta (Marigold flower) extract as a green inhibitor,” Corros. Sci., vol. 85, pp. 352-363, 2014.

[31] S. M. Tawfik, "Ionic liquids based gemini cationic surfactants as corrosion inhibitors for carbon steel in hydrochloric acid solution," J. Mol. Liq., vol. 216, pp. 624-635, 2016.

Nanthini Raman curently undertaking MSc by research at Universiti Teknologi PETRONAS.Author completed her degree in Bachelor of Chemical Engineering, majoring in Petrochemical Engineering at Universiti Teknologi PETRONAS, Perak, Malaysia (2017).Current research focuses on developing environmental friendly inhibitor to reduce the corrosion rate of carbon steel in corrosive medium. 